\title{
POLYSULFONE/POLYVINYLIDENE FLUORIDE COMPOSITE MEMBRANE: EFFECT OF COATING DOPE COMPOSITION ON MEMBRANE CHARACTERISTICS AND PERFORMANCE
}

\author{
N. Kusumawati ${ }^{1 * *}$, P. Setiarso ${ }^{1}$ and S. Muslim ${ }^{2}$ \\ ${ }^{1}$ Department of Chemistry, Universitas Negeri Surabaya, Ketintang Surabaya 60231, Indonesia \\ ${ }^{2}$ Department of Electrical Engineering, Universitas Negeri Surabaya, Ketintang Surabaya 60231, \\ Indonesia \\ *E-mail: nkusumawati82@yahoo.com
}

\begin{abstract}
The asymmetric polysulfone/polyvinylidene fluoride composite membranes with vary polyvinylidene fluoride levels in coating dope were prepared by non-solvent induced phase separation. $\mathrm{N}$-methyl pyrrolidinone and distilled-water were used as a combination of solvent and non-solvent, while ammonium chloride was applied as a porogenic additive in the system. Physical characteristics of the prepared membranes were analyzed using a scanning electron microscope. The membranes performance was analyzed in term of pure water flux, porosity, mechanical properties respectively. Results showed a good interaction between polyvinylidene fluoride material and polysulfone matrix. The polyvinylidene fluoride coating on the polysulfone matrix has increased the small pore quantity in the skin layer and strengthened the mechanical strength of the membrane. In addition, increased porosity with increasing doses of polyvinylidene fluoride in the dope solution does not necessarily increase the pure water flux of the membranes.

Keywords: membranes, polyvinylidene fluoride, polysulfone, composite, coating
\end{abstract}

(C) RASĀYAN. All rights reserved

\section{INTRODUCTION}

Polysulfone (PSf) is a high-performance polymer type with excellent chemical and thermal resistance, mechanical properties, high glass transition temperature and good film formation characteristics. . $^{1,23,4,5,6,7}$ These advantages made the PSf widely selected as the main material in the development of the separation membrane. ${ }^{8}$ Based on its high chemical, thermal, and mechanical resistance, PSf has been widely used as a major polymer in microfiltration (MF) and ultrafiltration (UF) membranes manufacturing, and has also been used as a support solid on nanofiltration (NF) and reverse osmosis (RO) membranes. ${ }^{9,10}$

Despite the scale of application development is quite large, the PSf has some disadvantages associated with symmetry structure. The symmetric structure membrane has a higher resistance to mass transfer so that it has a higher fouling tendency compared to that of asymmetry. The classic solution to solve this problem is by modifying the surface of the PSf membrane, including coating, grafting, and chemical treatment on membrane surfaces, with other polymers having asymmetric pore structures such as polyvinylidene fluoride (PVDF). ${ }^{11,12}$

As with PSf, PVDF has been extensively used in MF and UF membrane fabrication because of its excellent chemical and thermal stability, mechanical characteristics, and processing capabilities. ${ }^{13,14,15,16}$ PVDF is resistant to almost entire acids, also the oxidative environment. Nevertheless, the excellent chemical resistance of PVDF does not apply to strong alkaline, ester also ketone solutions. ${ }^{17,18,19,20}$ In contrast to these conditions, PSf has the better chemical stability to bases. Reference ${ }^{19,20,21}$ examined the chemical resistance of the PSf/PVDF membranes. The result showed the better resistance of the membranes in acidic environments. On the contrary, the weak resistance in an alkaline environment is indicated by the discoloration of the membrane became darker. This condition is induced by dehydrofluorination in PVDF polymer chains which resulted in the formation of $\mathrm{C}=\mathrm{C} .{ }^{17,22,23}$ The blending

Rasayan J. Chem., 11(3), 1034-1041(2018)

http://dx.doi.org/10.31788/RJC.2018.1133020

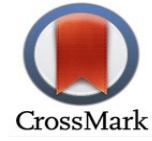


of PSf and PVDF as the main ingredients for membrane forming will produce nascent materials with enhanced performance and chemical stability.

Earlier researcher ${ }^{12}$ showed a characteristical asymmetry structure of PSf/PVDF coated membrane with higher permeability and acid resistance than PSf. The addition of PVDF material into the PSf dope solution has created a sponge pore structure with a denser pore size on the skin layer and finger pore with a more tenuous pore size on the membrane sublayer. Further, solubility parameters differences between PSf ( $\left.\delta \mathrm{t} 22.93 \mathrm{MPa}^{1} / 2\right)$ and NMP solvents $\left(\delta \mathrm{t} 22.96 \mathrm{MPa}^{1 / 2}\right)$ which closer than PVDF $\left(\delta \mathrm{t} 32.13 \mathrm{MPa} \frac{1}{2}\right)$ have induced better PSf solubility in NMP and led to the formation of PSf matrix substituted by PVDF particles. However, the magnitude of the macrovoid volume that arises as a result of increasing the sublayer thickness of the PSf matrix by minimum interaction with the PVDF substituent becomes the main disadvantage of PSf/PVDF coated membrane. Therefore, it is important to further research on the manufacture of asymmetric PSf/PVDF composite membranes with minimal macrovoid structures.

In order to improve the membrane characteristics, it was planned to combine the characteristics of the PSf and PVDF through other surface modification methods, i.e coatings. In this experiment, PSf/PVDF composite membranes were prepared by wet coating techniques where physical interactions will occur at the interface of the two miscible liquids. The PSf dope solution is dispersed in NMP and coated with PVDF to preparing the novel PSf/PVDF composite membrane by NIPS. The newly prepared ultrafiltration membrane is characterized by Scanning Electron Microscope (SEM). The membranes performance was evaluated in term of PWF, porosity, mechanical properties respectively. To the best of our knowledge, this is the first study on the effect of PVDF level on PSf/PVDF coated membrane and their possible applications for the water treatment.

\section{Material and Methods}

\section{EXPERIMENTAL}

PSf ( $\mathrm{d}=1,24 \mathrm{gmL}^{-1}$ at $25^{\circ} \mathrm{C}$, Mw 35,000) and 1-Methyl-2-pyrrolidone (NMP, $\left.\geq 99.7 \%\right)$ were provided by Sigma Aldrich Singapore. PVDF (Mw 354,000) and ammonium chloride $\left(\mathrm{NH}_{4} \mathrm{Cl}\right.$, powder, $\left.\geq 99.5 \%\right)$ were obtained each from Aldrich Singapore and Riedel de Haen China. The non-woven gauze (254 mesh) was provided by Kasa Husada Indonesia.

\section{General Procedure of Membrane Preparation}

PSf, PVDF, and PSf/PVDF composite membranes were prepared by the non-solvent induced phase separation method. PSf dope solution was prepared followed the composition of PSf/NMP/ $/ \mathrm{NH}_{4} \mathrm{Cl}$ (wt.\%) 16/84/0. While, for preparing the PVDF coating dope, in a different place a certain composition of $\mathrm{NH}_{4} \mathrm{Cl}$ (0 wt $\%$ - $14 \mathrm{wt} \%$ of PVDF level) were dissolved in NMP. To optimize porogen solubility was performed stirring for $0.5 \mathrm{~h}$ at $60{ }^{\circ} \mathrm{C}$. PVDF was mixed to the previously stirred solution and continued stirring for $6.5 \mathrm{~h}$ to guarantee the membrane constituent particles solubility. Each of the dope solutions was aged for $18 \mathrm{~h}$ before being cast to obtain an air bubble-free dope solution. This action could reduce potential defects in membranes. The PSf dope solutions were superimposed on the gauze supporting layer using an automatic-casting knife with a thickness of $800 \mu \mathrm{m}$. While PVDF coating was carried out by the same method over a PSf film layer with a thickness of 1,000 $\mu \mathrm{m}$ (measured from the base). Before immersion in non-solvent $\mathrm{H}_{2} \mathrm{O}$, the cast solution was aged for 30 minutes and immediately afterward the cast solution was inserted into a coagulation bath for $2 \mathrm{~h}$. Table-1 showed an overview of the PSf dope and PVDF coating dope composition used in the research.

Table-1: An Overview of the Membrane Dope Solution Composition

\begin{tabular}{c|c|c|c|c}
\hline \multirow{2}{*}{ Type } & \multicolumn{4}{|c}{ Compositions (wt.\%) } \\
\cline { 2 - 5 } & PSf & PVDF & NMP & $\mathrm{NH}_{4} \mathrm{Cl}$ \\
\hline PSf/PVDF-0 & 16 & 2 & 84 & 14 \\
\hline PSf/PVDF-1 & 16 & 4 & 84 & 12 \\
\hline PSf/PVDF-2 & 16 & 6 & 84 & 10 \\
\hline PSf/PVDF-3 & 16 & 8 & 84 & 8 \\
\hline
\end{tabular}


RASĀYAN J. Chem.

Vol. 11 | No. 3 |1034 - 1041 | July - September | 2018

\begin{tabular}{c|l|l|l|l}
\hline PSf/PVDF-4 & 16 & 10 & 84 & 6 \\
\hline PSf/PVDF-5 & 16 & 12 & 84 & 4 \\
\hline PSf/PVDF-6 & 16 & 14 & 84 & 2 \\
\hline PSf/PVDF-7 & 16 & 16 & 84 & 0 \\
\hline
\end{tabular}

\section{Membranes Characterization Method Permeation flux (PWF)}

The PWF of the composite membranes was measured by a self-made dead-end reactor $(0.1 \mathrm{MPa}$; room temperature). The permeate volume $[V(\mathrm{~L})]$ was obtained at working time $[t(\mathrm{~h})]$ through a membranes unit area $\left[A\left(\mathrm{~m}^{2}\right)\right]$. PWF $\left(\mathrm{Lm}^{-2} \mathrm{~h}^{-1}\right)$ was calculated using equation (1).

$$
P W F=\frac{V}{A x t}
$$

\section{Porosity (P)}

The porosity of the membranes was measured by gravimetry method. Membranes that have been treated in distilled water and cleaned using filter paper to remove residual water on the surface then weighed to obtain wet weight. Prior to the measurement of dry weight, the membrane was dried using an oven with air circulation $\left(60^{\circ} \mathrm{C} ; 24 \mathrm{~h}\right)$ and continued with vacuum oven $\left(80^{\circ} \mathrm{C} ; 24 \mathrm{~h}\right)$. Based on the weight data (wet and dry), membrane porosity was calculated by equation (2).

$$
P(\%)=\frac{W_{W}-W_{d}}{p_{w} x A x \delta} \times 100
$$

Where, $P$ was the membrane porosity, $W_{w}$ and $W_{d}$ each was the membrane wet and dry weight $(\mathrm{g})$, whereas $\rho_{W}$ and $A$ respectively was the pure water density $\left(\mathrm{g} / \mathrm{cm}^{3}\right)$ and wet membrane thickness $(\mathrm{cm})$. To minimize experimental error, applied three times measurement replication and calculated on average. ${ }^{24}$

\section{Morphological Studies}

The membrane surface and cross-sections morphology was analyzed using SEM (Zeiss EVO MA10, Germany). Particularly for cross-section analysis, it will be preceded by the treatment of membranes in liquid nitrogen and coating with gold using a sputtering method. The upper surface of the cross-sectional morphology represents the membrane skin layer (the membrane side which has direct contact with the non-solvent water), while its bottom surface presented is a membrane porous layer which generally consists of micropores and macrovoids. The membrane morphology was analyzed with a $200 \mathrm{kV}$ acceleration voltage. ${ }^{24}$

\section{Tensile Strength and Elongation}

The mechanical characteristics of the membrane were evaluated using a tensile tester (RCT/10KN/AF TOYO SEIKI, Japan). The PSf/PVDF composite membrane to be evaluated was dried at $30{ }^{\circ} \mathrm{C}$ for $24 \mathrm{~h}$ and then being cut to size $15 \mathrm{~mm} \times 100 \mathrm{~mm} \cdot{ }^{24}$ The clipping distance is kept constant at $50 \mathrm{~mm} .{ }^{25}$ The analysis was performed with $20 \mathrm{~mm} / \mathrm{min}$ strain rate. The value of tensile strength and elongation resulted from the averages of three samples While a mechanical strength value obtained from the ratio of tensile strength to elongation.

\section{Morphological Studies}

\section{RESULTS AND DISCUSSION}

SEM analysis becomes one of the main technique that can be used to study the membrane morphology because it is able to provide qualitative information related to the characteristics of pore structure on the surface and cross-section of the obtained membrane. The cross-sectional morphology of the PSf/PVDF coated membrane with different PVDF levels was present in Fig.-1 (f, g, h). 
RASĀYAN J. Chem.

Vol. 11 | No. 3 |1034 - 1041 | July - September | 2018

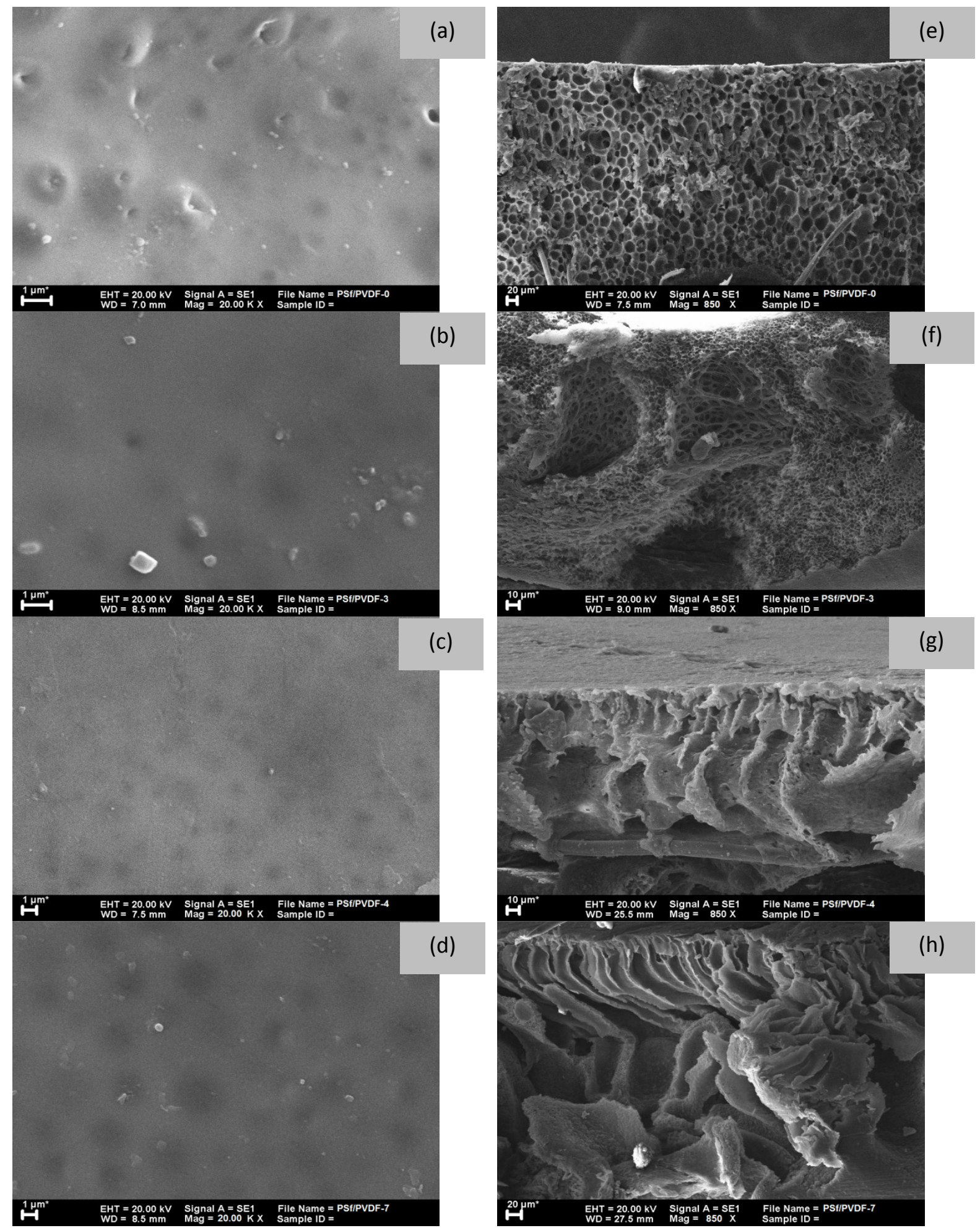

Fig.-1: SEM Images of Membranes: (a), (b), (c), and (d) are the surface morphology of PSf/PVDF-0, PSf/PVDF-3, PSf/PVDF-4, PSf/PVDF-7 and e), f), g), and h) are the cross-section morphology of PSf/PVDF-0, PSf/PVDF-3, PSf/PVDF-4, PSf/PVDF-7 respectively

It is shown in Fig.-1 (f, g, h) that the PSf/PVDF-3; PSf/PVDF-4; and PSf/PVDF-7 membranes all have an asymmetric pore structure composed of a dense skin layer (part which has direct contact with non-solvent water) and porous sublayer (supporting layer, part attached to a glass). The skin layer performs the 
separation function, while the porous layer was responsible for the membrane mechanical properties. In the sublayer of the composite membrane, there appears a finger-like pore presence near the upper and macrovoids close to the lower of the sublayer. The number of finger-like pores increases with increasing levels of PVDF. Nevertheless, it appears that the length of finger-like pores was getting shorter and macrovoids have also appeared smaller and less prominent.Changes in pore size induced by elevated levels of PVDF is due to the high mutual affinity between NMP and water that has resulted in instantaneous demixing resulting in finger-like pores formation on the membrane sublayer. The presence of PVDF in the coating layer had influences where the PVDF plays a role in improving surface tension of the water and membrane dope interface. These conditions affect the liquid-liquid demixing rate that occurs during phase separation, also affected the precipitation kinetics and membrane morphology as a consequence. The PVDF materials were more hydrophobic than PSf. When treated in the coagulation medium (non-solvent), the PVDF materials was able to withstand the water diffusion flow rate due to its hydrophobic properties, while the PSf had a lower compatibility with the solvent (NMP) thus contributing accelerated the liquid-liquid demixing process between solvent and non-solvent. This condition has an effect on increasing the pore quantity on the membrane.

Membranes surface morphology with varying PVDF levels were shown in Fig.-1 ("a","b","c","d"). These images showed the very dense membrane top surface which dominated by pores that are even too small to be observed at 20000 magnification. Such surface morphologies were formed by the instantaneous demixing and rapid precipitation process of the dope solution.

\section{Effect of PVDF level on Membrane Porosity}

Membrane porosity is one of the important parameters affecting the permeation and separation rates and it is closely related to PWF and membrane morphology. The porosity of PSf/PVDF composite membranes with varying PVDF levels was shown in Fig.-2. In Fig.-2 it appears that an increase in PVDF level has increased porosity from $30.32 \%$ for PSf/PVDF-0 membrane to $65.74 \%$ for PSf/PVDF-3 membrane and then decreased to $55.81 \%$ for PSf/PVDF-4. This is due to the increasing density of space by the increase of PVDF particles in the same coating area has provided sufficient driving force for PVDF particle penetration into the empty space formed between PSf-PSf particles, thus creating additional space between PSf particles. This may occur given the presence of PVDF in the coating dope is also accompanied by NMP solvents and $\mathrm{NH}_{4} \mathrm{Cl}$ porogens, allowing the creation of the same vacant space between PVDF-PVDF particles which will become pore as soon as the phase inversion process is completed.

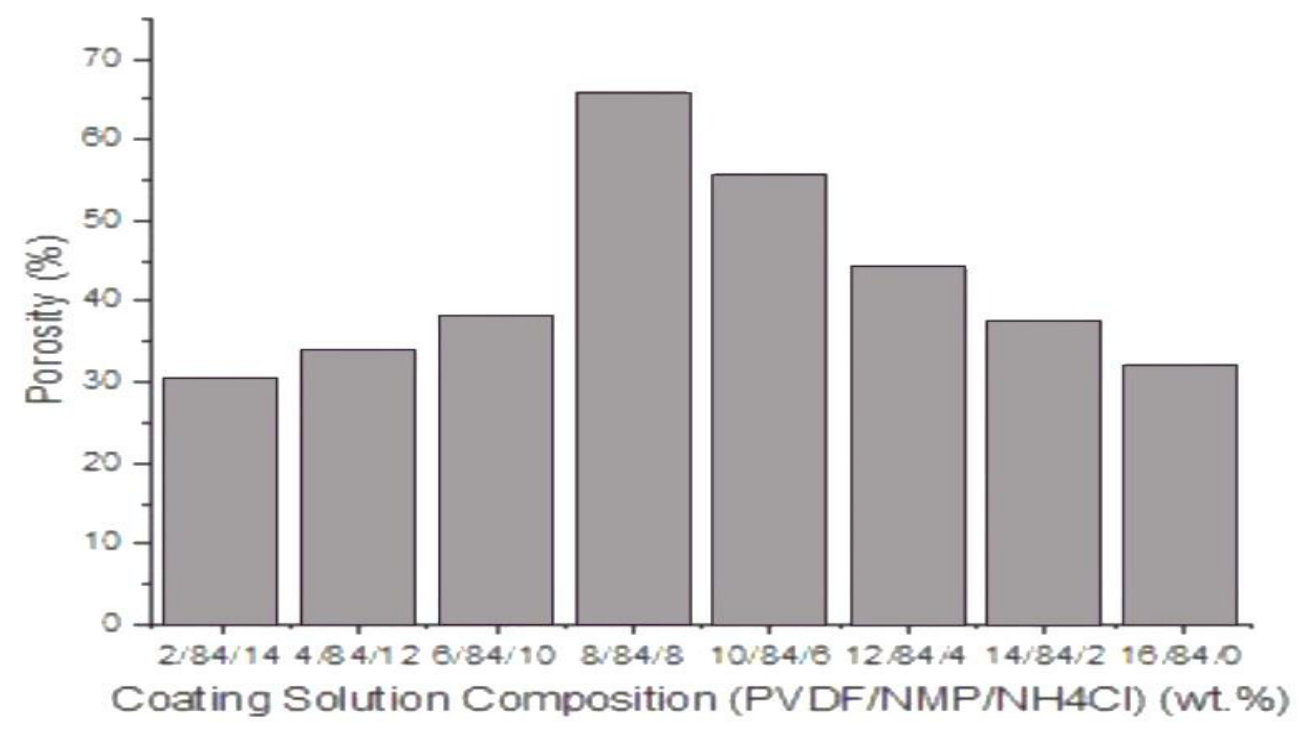

Fig.-2: The Membrane's Porosity

However, the same penetration range into the empty space between PSf particles accompanied by further increases in PVDF levels in the coating dope has resulted in increasingly tight interactions between the 
membrane polymer particles and again resulting in a decrease in the pore number (porosity) of the membrane concerned. The decrease of porosity as the increase of PVDF level in the coating dope reached its peak when the membrane coating process used 16 (wt.\%) PVDF, which detected porosity percentage which only reached $32.16 \%$.

\section{Effect of PVDF level on Membrane Permeability and Pore Size}

Pure water flux and pore size were the two main determinant factors of porous membranes performance. Pure water flux was closely related with a membrane pores number and size. ${ }^{8,9}$ An influence of PVDF level on PWF of composite membranes were shown in Fig.-3. In Fig.-3 it appears that PWF decreased from 15,233 $\mathrm{Lm}^{-2} \mathrm{~h}^{-1}$ for PSf/PVDF-1 to 5,273 $\mathrm{Lm}^{-2} \mathrm{~h}^{-1}$ for PSf/PVDF-3 membrane and further only amounted to $231 \mathrm{Lm}^{-2} \mathrm{~h}^{-1}$ for PSf/PVDF-7 membrane.

Data in Fig.-3 shows a decrease in PWF of membranes along with elevated PVDF levels in the coating dope composition. Decreased pure water permeability is a combined effect of a porosity and pore size changes on PSf/PVDF coated membranes. In addition, the deterioration of pure water permeability of PSf/PVDF membranes along with increasing PVDF levels in a coating dope from 2(wt.\%) to 10(wt\%) occurring together with an increase in membrane porosity shows that not all of the pores present in the coating process with the specific coating composition is capable of producing interconnected pores or connecting to the lower surface of the membrane. This condition affects the pace of pure water in penetrating the membrane. In addition, the presence of a small pore dominating on the membrane has enabled a decrease in pure water permeability at the same time as an increase in membrane porosity. Fig. -4 shows the pore size of the prepared membrane with elevated PVDF levels in the coating dope.

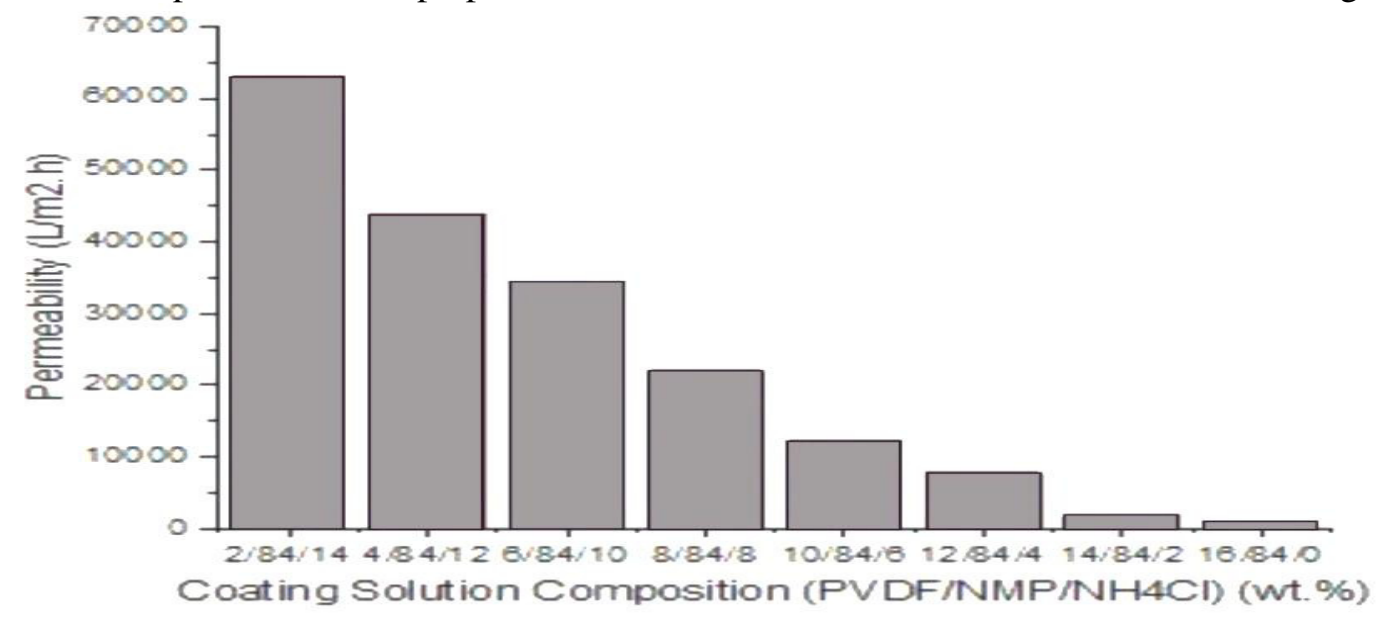

Fig.-3: The Membrane's Permeability

\section{Effect of PVDF level on Membrane Mechanical Characteristic}

Young's modulus that are important parameters to describe the membrane mechanical properties as shown in Fig.-5. Along with increasing levels of PVDF, Young's modulus increased from $764 \mathrm{~N} / \mathrm{m}^{2}$ for PSf/PVDF-0 membrane to 1,486 N/m² for PSf/PVDF-3 membrane and reached its peak of 7,582 N/m for PSf/PVDF-7 membrane. The increase in membrane Young's modulus occurs along with the increased porosity of PSf/PVDF coated membrane prepared by the coating process using 2 (wt.\%) to 10 (wt.\%) PVDF occurs due to the dominance of the small pores in the porous support layer of the membrane. The Young's modulus of the membrane prepared with elevated PVDF levels in the coating dope is shown in Fig.-5.

\section{CONCLUSION}

Flat sheet PSf/PVDF composite membranes with varying level of PVDF were prepared using NIPS with $\mathrm{NH}_{4} \mathrm{Cl}$ as a porogenic additive. The influence of the PVDF levels on the physical and mechanical characteristics as well as performance was investigated. The results can be summarized as follows.

1. The entire PSf/PVDF coated membranes were known to form an asymmetric pore. 
2. Some portions of PVDF have a good dispersion ability as coating particles in the PSf matrix.

3. The coating of PVDF in PSf matrix can improve the quantity of a small pore in the skin layer.

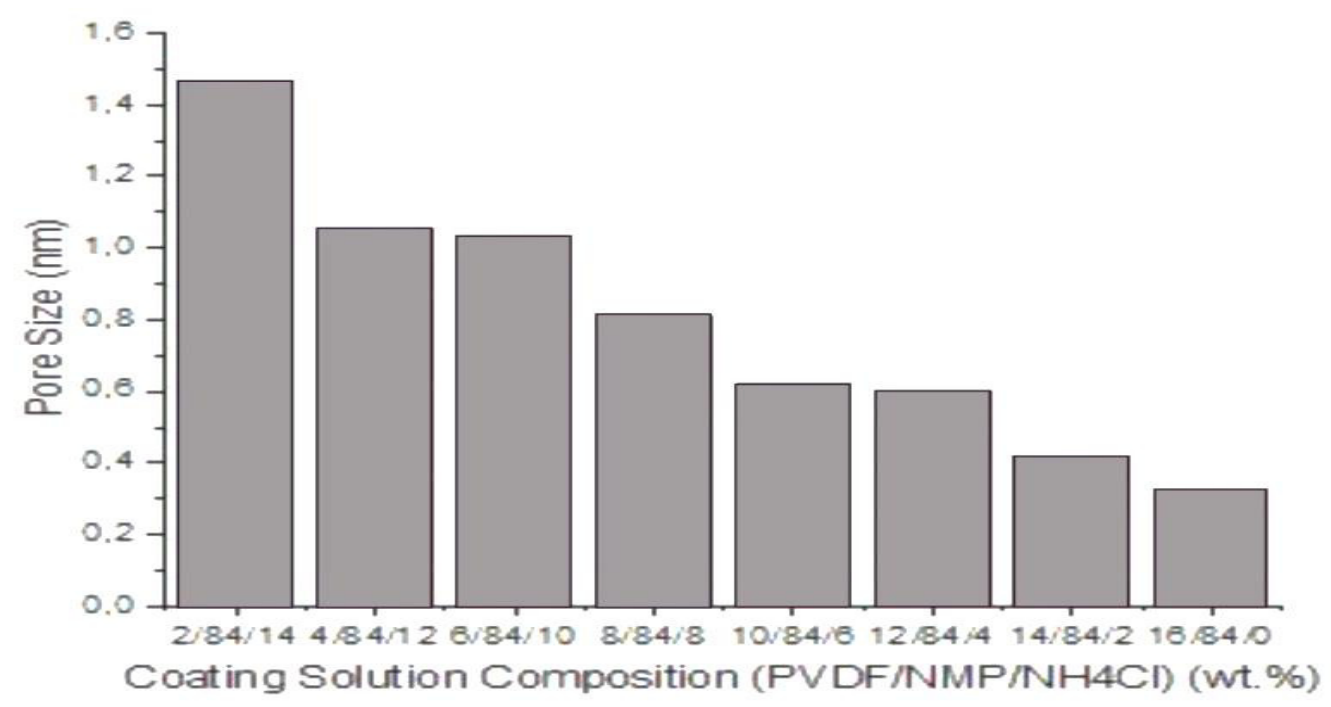

Fig.-4: The Membrane's Pore Size

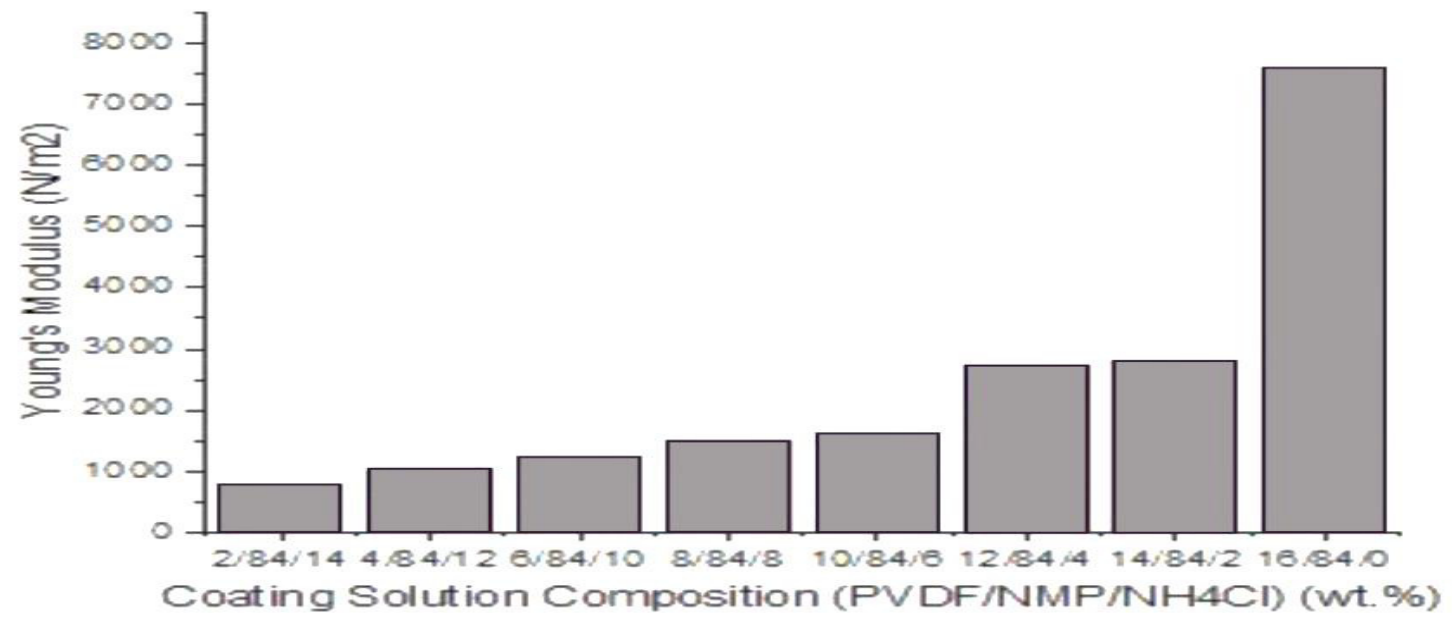

Fig.-5: The Membranes Young's Modulus

4. The increase in PVDF level from 2(wt\%) to 10(wt.\%) in the coating dope can improve the porosity, while the increase in PVDF level from 12(wt\%) to 16(wt.\%) can reduce the porosity of the prepared membrane.

5. The increase of PVDF level in the coating dope can reduce the PWF of the prepared membranes.

6. The PVDF coating particles addition has strengthens the mechanical strength of the prepared membranes.

\section{ACKNOWLEDGMENT}

The authors acknowledge the financial support by the Indonesian Ministry of Higher Education, Research and Technology.

\section{REFERENCES}

1. C. Dizman, M.A. Tasdelen, Y. Yagci, Polym. Int., 62, 991(2013)

2. Y. Gao, B. Li, L. Zhong, L. Zhang, Z. Ding, Vaccum, 107, 199(2014), DOI: 10.1016/j.vaccum.2014.01.029 
RASĀYAN $J$. Chem.

Vol. 11 | No. 3 |1034 - 1041 | July - September | 2018

3. W.J. Lau, A.F. Ismail, N. Misdan, M.A. Kassim, Desalination, 278, 190(2012), DOI: 10.1016/j.desal.2011.04.004

4. A. Mathkar, C. Aichele, I. Omole, N. Singh, D. Hashim, H. Gullapalli, RSC Adv., 3, 4216 (2013)

5. N. Kusumawati, P. Setiarso, M.M. Sianita, S. Muslim, Indones. J. Chem., 18(2), 257(2018), DOI: 10.22146/ijc.27272

6. Gustian, Ghufira, D. Oktiarni, Rasayan J. Chem., 10, 689(2017), DOI: 10.7324/RJC.2017.1031716

7. I. Gustian, Asdim, E. Maryanti, Rasayan J. Chem, 9, 608(2016)

8. S.Y. Cheng, D.I. Oatley, P.M. Williams, C.J. Wright, Adv. Colloid Interface Sci., 164, 12(2011), DOI: 10.1016/j.cis.2010.12.010

9. J.Y. Kim, H.K. Lee, S.C. Kim, J. Membr. Sci., 163, 159(1999), DOI: 10.1016/S03767388(99)00164-7

10. Y. Zhang, J. Wang, F. Gao, H. Tao, Y. Chen, H. Zhang, Sep. Purif. Tech., 30, 1(2016)

11. S.R. Panda, S. De, Desalination, 347, 52(2014), DOI: 10.1016/j.desal.2014.05.030

12. R.D.C. Ningrum, N. Kusumawati, Int. J. Adv. Sci. Eng. Inform. Tech., 6, 716(2016), DOI: 10.18517/ijaseit.6.5.911

13. P.S. Malcolm, Polymer Chemistry: An Introduction, Oxford University Press, London, p. 87-91 (1999)

14. A. Rahimpour, M. Jahanshahi, B. Rajaeian, M. Rahimnejad, Desalination, 278, 343(2011), DOI: 10.1016/j.desal.2011.05.049

15. Y. Zhang, J. Zhao, H. Chu, X. Zhou, Y. Wei, Desalination, 344, 71(2014), DOI: 10.1016/j.desal.2014.03.007

16. C. Sun, X. Feng, Sep. Purif. Tech., 185, 94(2017), DOI: 10.1016/j.seppur.2017.05.022

17. F. Liu, A.N. Hashim, Y. Liu, M.R.M. Abed, K. Li, J. Membr. Sci., 375, 1(2011), DOI: 10.1016/j.memsci.2011.03.014

18. Zeman and Zydney.. Microfiltration and Ultrafiltration: Principles and Applications. Marcel Dekker, New York, p. 1-10 (1996)

19. N. Kusumawati, T. Koestari, S. Muslim, Res. J. Pharm. Biol. Chem. Sci., 7, 69(2016)

20. N. Kusumawati, P.Setiarso, S. Muslim, N. Purwidiani, Rasayan J. Chem., 11(1), 260(2018), DOI: 10.7324/RJC.2018.1112018

21. N. Kusumawati, T. Koestari, S. Muslim, Res. J. Pharm. Biol. Chem. Sci., 7, 69(2016)

22. M.F. Rabuni, N.M.N. Sulaiman, M.K. Aroua, N.A. Hashim, Ind. Eng. Chem. Res., 52(45), 15874(2013)

23. G.J. Ross, J.F. Watts, M.P. Hill, P. Morrissey, Polymer, 42, 403(2001), DOI: 10.1016/S00323861(00)00328-1

24. Y. Ma, F. Shi, Z. Wang, M. Wu, J. Ma, C. Gao, Desalination, 286, 131(2012), DOI: 10.1016/j.desal.2011.10.040

25. Gao. J, Sun. S.P, Zhu. W.P, Chung. T.S, Water Research, 63, 252(2014), DOI10.1016/j.waters.2014.06.006

[RJC-3020/2018] 